\title{
Development and Production of 18Mn-18Cr Non-magnetic Retaining Ring with High Yield Strength
}

\author{
Katsutoshi ORITA, ${ }^{1)}$ Yasumi IKEDA, ${ }^{1)}$ Tadao IWADATE2) and Junji ISHIZAKA ${ }^{2)}$ \\ 1) Power Generation Equipments \& Materials Section, Muroran Plant, The Japan Steel Works, Ltd., Chatsumachi, Muroran, Hokkaido, 051
} Japan. $\quad$ 2) Research Laboratory, Muroran Plant, The Japan Steel Works, Ltd., Chatsumachi, Muroran, Hokkaido, 051 Japan.

(Received on December 14, 1989; accepted in the final form on April 20,1990)

\begin{abstract}
Retaining ring for electric generator is required to have non-magnetism, high strength, high ductility and stress corrosion cracking (SCC) resistance. Several kinds of materials for non-magnetic retaining ring have been developed and recently $18 \% \mathrm{Mn}-18 \% \mathrm{Cr}$ austenitic steel which has been developed to improve susceptibility to SCC of $18 \% \mathrm{Mn}-5 \% \mathrm{Cr}$ austenitic steel has begun to use. $18 \% \mathrm{Mn}-18 \% \mathrm{Cr}$ steel contained high nitrogen content has been investigated as the material with high strength, high ductility and SCC resistance. On the base of the fundamental studies of chemical composition and cold work on increasing yield strength of $18 \% \mathrm{Mn}-18 \% \mathrm{Cr}$ steel, a trial $18 \% \mathrm{Mn}-18 \% \mathrm{Cr}$ retaining ring with yield strength $1400 \mathrm{MPa}$ was successfully manufactured and mechanical properties, fatigue strength, fracture toughness and SCC were investigated for the trial ring material.
\end{abstract}

KEY WORDS: austenitic; non-magnetic; strength; ductility; toughness; stress corrosion cracking; retaining ring.

\section{Introduction}

For improvement of the susceptibility to $\mathrm{SCG}$ of $18 \% \mathrm{Mn}-5 \% \mathrm{Cr}$ austenitic steel $(18-5)^{1,2)}$ which has been widely used for non-magnetic retaining ring $(\mathrm{R} / \mathrm{R})$ material, $18 \% \mathrm{Mn}-18 \% \mathrm{Cr}$ austenitic steel (1818) have been investigated. In order to avoid SCC caused by grain-boundary carbides which are associated with 0.4 to $0.6 \mathrm{wt} \%$ carbon content of $18-5$ specified in ASTM A 289 class B, carbon content of 18-18 was reduced to maximum $0.13 \mathrm{wt} \%$ as specified in ASTM A 289 class G. $18-5$ and 18-18 are austenitic steels, so their strengthening is due to solution and cold worked hardening. Reducing carbon content of 18-5 will result in lower austenite stability and solution hardening. This can be offset by the replacement of carbon with another interstitial element, nitrogen. The chromium content has been increased in order to increase nitrogen solubility ${ }^{3)}$ and improve corrosion resistance. In this way, 18-18 material for $\mathrm{R} / \mathrm{R}$ has been developed.

Recently there is a great demand for higher strength 18-18 R/R. The specified $0.2 \%$ yield strength has increased as maximum unit capacity of generator increases, as shown in Fig. 1. For increasing of unit capacity, the diameter of generator and $\mathrm{R} / \mathrm{R}$ increase. As a result, $0.2 \%$ yield strength required for $R / R$ increases, because stress occurred in $R / R$ is directly proportional to multipling by diameter. ${ }^{4)}$

Effects of chemical composition of 18-18 on mechanical properties have been studied. This paper describes that a trial R/R with yield strength 1400 $\mathrm{MPa}$ (YS $1400 \mathrm{MPa}$ ) was manufactured by 18-18 which material was fundamentally studied on the effect of chemical composition and cold work ratio on mechanical properties and SCG resistance, additionally various properties of the trial $R / R$ material are investigated.

\section{Fundamental Studies-Chemical Composi- tion \& Cold Work-}

\subsection{Experimental Procedure}

One of important requirements for non-magnetic $\mathrm{R} / \mathrm{R}$ materials is stable austenite structure without magnetic structure of delta ferrite. Effects of chemical composition on austenite stability of high $\mathrm{Mn}-\mathrm{Cr}$ austenitic steels were studied using 20 heats which were made from $50 \mathrm{~kg}$ VIM-ingots, forged by hammer to $40 \mathrm{~mm}$ square block (forging ratio approx. $12 \mathrm{~S}$ ) and then solution-treated at $1050^{\circ} \mathrm{C}, 2 \mathrm{~h}$. Delta ferrite contents were determined by magnetic method.

Strengthening method of 18-18 was studied on solution hardening due to nitrogen and carbon elements and cold work hardening. Effects of nitrogen and carbon content of 18-18 on mechanical properties have been investigated by 5 heats which were made from $50 \mathrm{~kg}$ VIM-ingots. Chemical compositions of the heats are shown in Table 1. Test samples were forged in $25 \mathrm{~mm}$ thickness, solution treated at 1040 ${ }^{\circ} \mathrm{C}, 2 \mathrm{~h}$ and water cooled. $14 \mathrm{~mm}$ diameter and 50 $\mathrm{mm}$ gauge length specimens are used for tensile test of solution treated specimens. Cold working were performed by stretched round specimens using tensile test machine up to specified cold work ratio at room temperature.

Mechanical properties were determined by the tensile specimens with $10 \mathrm{~mm}$ diameter and $50 \mathrm{~mm}$ gauge length which were made fram the stretched 


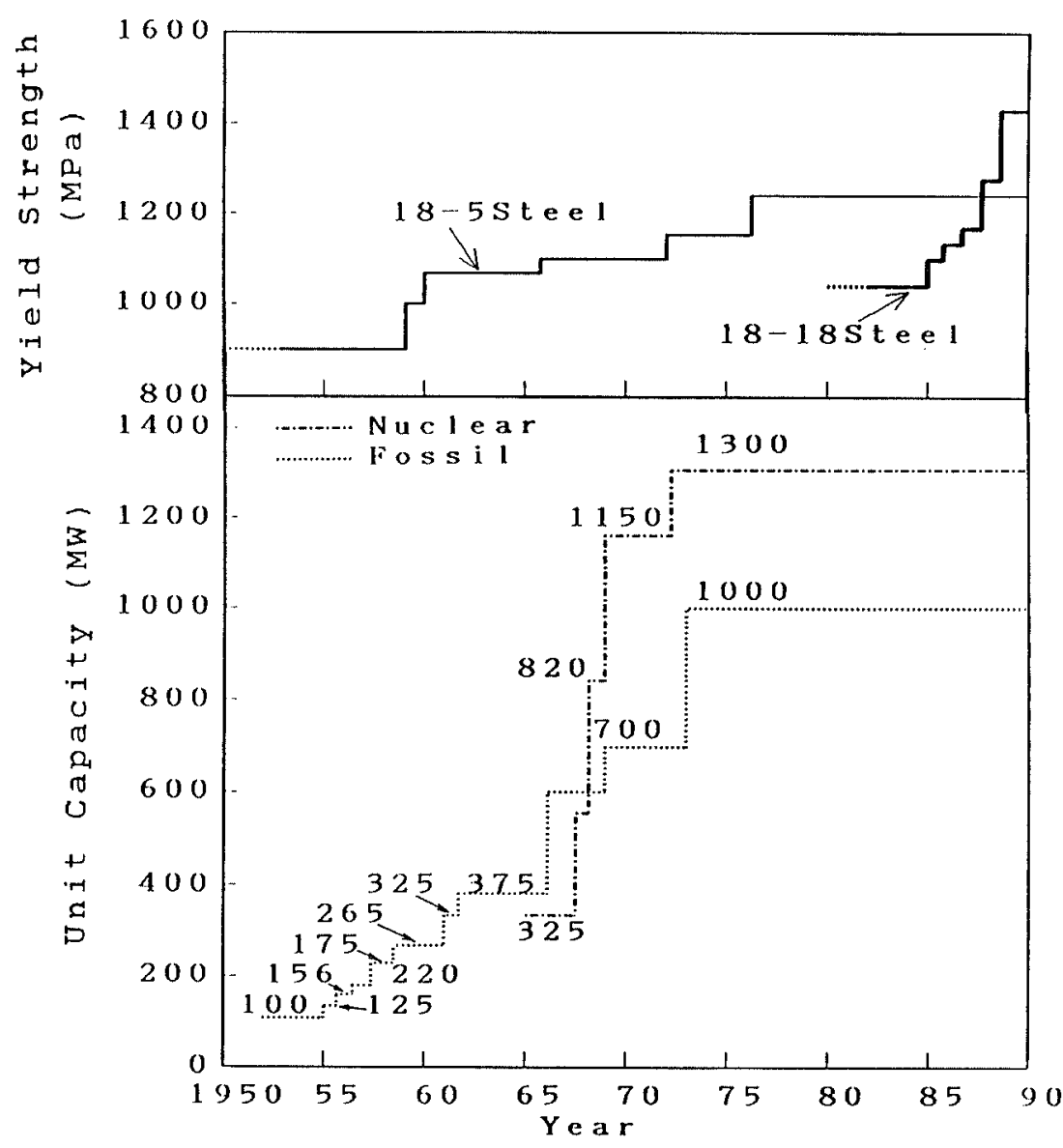

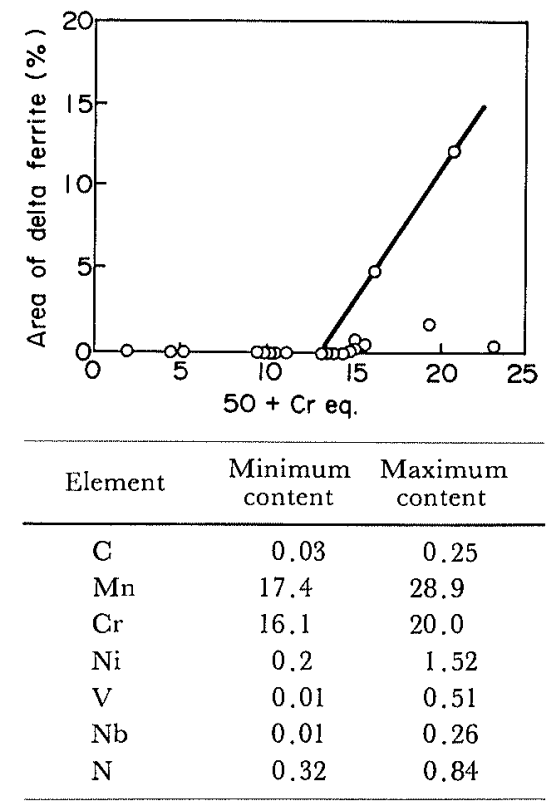

Fig. 2.

Relationship between chromium equivalent and delta ferrite content of $18 \% \mathrm{Mn}-$ $18 \% \mathrm{Cr}$ material after solution treated at $1050^{\circ} \mathrm{C}$.

Fig. 1. The transition of maximum specified $0.2 \%$ yield strength and maximum unit capacity of generator which have been manufactured in JSW.

Table 1. Chemical compositions of experimental heats for examination of mechanical properties and stress corrosion cracking properties.

\begin{tabular}{|c|c|c|c|c|c|}
\hline No. & $\mathrm{C}$ & $\mathrm{Mn}$ & $\mathrm{Cr}$ & $\mathrm{N}$ & Material \\
\hline 1 & 0.045 & \multirow{5}{*}{$\begin{array}{l}19.42 \\
19.81\end{array}$} & \multirow{5}{*}{$\begin{array}{c}19.33 \\
20.01\end{array}$} & 0.576 & Key \\
\hline 2 & 0.050 & & & 0.840 & \multirow{2}{*}{$\begin{array}{c}\text { Effect of } \\
\mathrm{N}\end{array}$} \\
\hline 3 & 0.047 & & & 0.719 & \\
\hline 4 & 0.150 & & & 0.555 & \multirow{2}{*}{ C } \\
\hline 5 & 0.250 & & & 0.575 & \\
\hline
\end{tabular}

round specimens. For studies of anisotropy of tensile properties, plate specimens which size are $70 \mathrm{~mm}$ width and $10 \mathrm{~mm}$ thickness are stretched by tensile test machine and small tensile specimens which size are $6 \mathrm{~mm}$ diameter and $30 \mathrm{~mm}$ gauge length, are used for longitudinal and perpendicular direction tests.

\subsection{Results and Discussion}

\subsubsection{Stability of Austenitic Structure}

The austenite stability is estimated with $\mathrm{Cr}$ equivalent $\left(C r_{\text {eq. }}\right)$. Fig. 2 shows the relationship between $\mathrm{Cr}_{\text {eq. }}$ and delta ferrite content of 18-18 after solution treated at $1050^{\circ} \mathrm{C}$. $C r_{\text {eq }}$. shall be calculated by Newhouse equation ${ }^{5)}$ as shown below.

$$
\begin{aligned}
C r_{\mathrm{eq} .}= & \mathrm{Cr}+6 \mathrm{Si}+4 \mathrm{Mo}+1.5 \mathrm{~W}+11 \mathrm{~V}+5 \mathrm{Nb} \\
& -(40 \mathrm{C}+2 \mathrm{Mn}+4 \mathrm{Ni}+2 \mathrm{Co}+30 \mathrm{~N})
\end{aligned}
$$

From these results, $50+C r_{\text {eq. }}$ should be less than 13 to avoid delta ferrite. Hsiao and Dulis studied the austenitic stability by means of high $\mathrm{Mn}-\mathrm{Cr}$ steel which were contained up to $0.8 \mathrm{wt} \% \mathrm{C}, 5$ to $28 \mathrm{wt} \%$ $\mathrm{Cr}, 12$ to $28 \mathrm{wt} \% \mathrm{Mn}, 0.1$ to $0.8 \mathrm{wt} \% \mathrm{~N}$ and reported precipitations of delta ferrite for high $\mathrm{Cr}$ steel, so the results correspond with our investigation. ${ }^{6)}$ Additionally, delta ferrite content is influenced by solution temperature. Fig. 3 shows the effect of solution temperature and chemical composition on delta ferrite content. Adding nitrogen more than $0.576 \mathrm{wt} \%$ is effective for stability of austenitic structure.

Though vanadium and niobium are effective for high strength because of grain fining element, those are not suitable for complete austenitic structure because of forming delta ferrite. Typical photographs of delta ferrite obtained on 18-18-0.502wt \% N, solution treated at $1050^{\circ} \mathrm{C}$ are shown in Fig. 4 in comparison with complete austenitic structure of 18-18$0.840 \mathrm{wt} \% \mathrm{~N}$ solution treated at $1050^{\circ} \mathrm{C}$.

\subsubsection{Mechanical Properties}

Mechanical properties in the solution treated state as a function of nitrogen and carbon content are plotted in Figs. 5 and 6, respectively. Tensile strength $(T S)$ and $0.2 \%$ yield strength $(Y S)$ increase with 


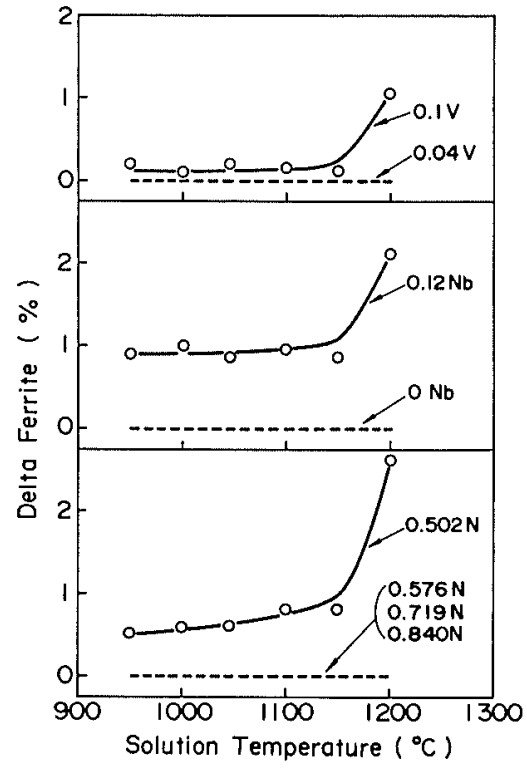

Fig. 3. The effect of solution temperature and chemical composition on delta ferrite content.

nitrogen and carbon content, respectively. Elongation $(E L)$ are almost independent of nitrogen and carbon content. Normally high nitrogen content brings out increasing strength and decreasing $E L$. In this investigation on nitrogen content of such small variation, effect of nitrogen content on $E L$ is not detected. On the other side, reduction of area $(R A)$ decreases slightly with carbon content and is almost independent of nitrogen content. Consequently, it is clear that nitrogen is effective for solution hardening without remarkable decreasing $E L$ and $R A$.

Figs. 7 and 8 show the effect of nitrogen and carbon content on mechanical properties of cold worked material, respectively. $Y S$ increases with cold work ratio and its tendency is obviously on high nitrogen and carbon content material. EL decreases as cold work ratio increases. However, $E L$ values of cold worked material are almost identical for either nitrogen or carbon content. This is because $E L$ in the solution treated state is almost independent of nitrogen or carbon content as shown in Figs. 5 and 6 .

The effect of nitrogen or carbon content on cold work response is explained schematically in Fig. 9. $Y S$ in high nitrogen or carbon content material is higher than $Y S$ in low nitrogen or carbon content material at same cold work ratio.

The anisotropy of tensile properties was investigated on cold worked 18-18-0.576wt $\% \mathrm{~N}$ and $18-18$ $0.840 \mathrm{wt} \% \mathrm{~N}$. Ratio of longitudinal $Y S(Y S-T)$ for cold worked direction and perpendicular $Y S(Y S-R)$ slightly decreases as cold work ratio increases, as shown in Fig. 10. Tensile properties anisotropy of higher nitrogen content and lower cold worked material is smaller than one of higher cold worked and lower nitrogen content material. Consequently, if nitrogen or carbon content of 18-18 increase, $Y S$ after cold working increases remarkably and $E L$ is not influenced. Accordingly, in order to manufacture high $Y S$ 18-18 $\mathrm{R} / \mathrm{R}$ it is effective industrially to be

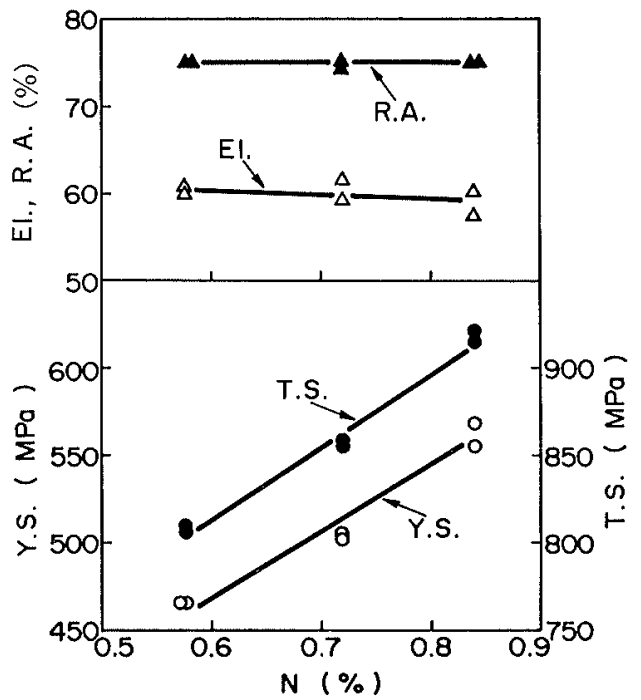

Fig. 5. Mechanical properties in the solution treated state as a function of nitrogen content.

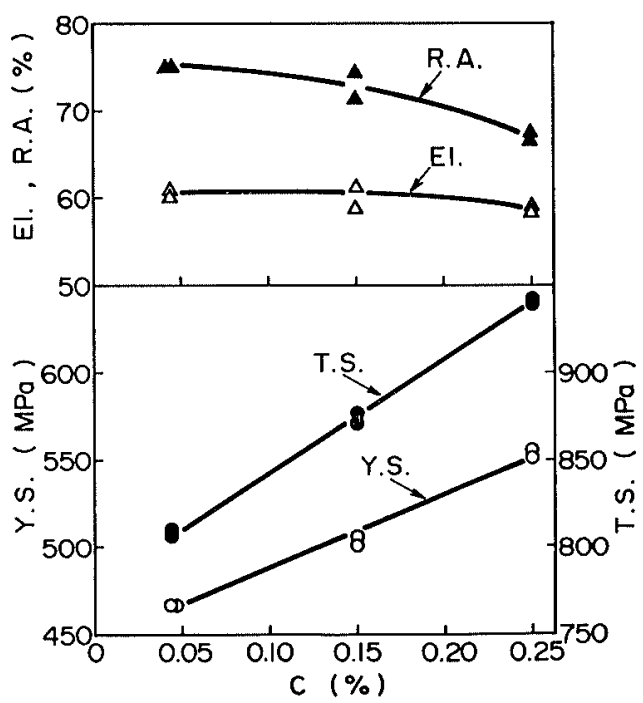

Fig. 6. Mechanical properties in the solution treated state as a function of carbon content. 
ISIJ International, Vol. 30 (1990), No. 8

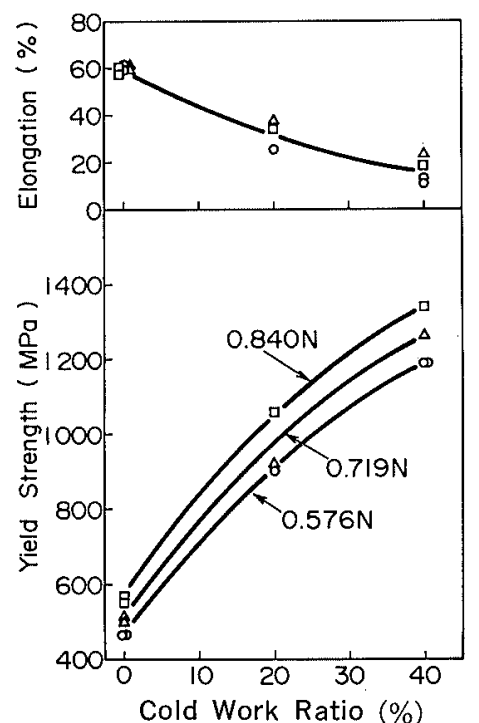

Fig. 7. The effect of cold work ratio and nitrogen content on elongation and yield strength.

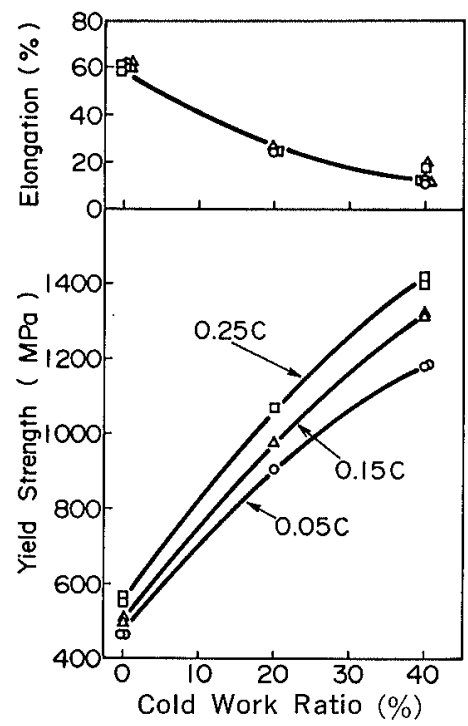

Fig. 8. The effect of cold work ratio and carbon content on elongation and yield strength.

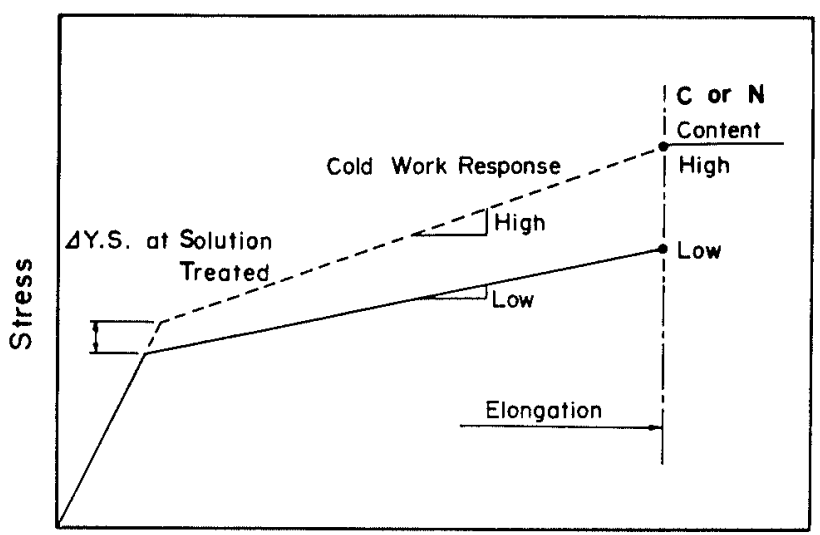

Fig. 9. Schematic explanation of the effect of nitrogen or carbon content on stree-strain curve of $18 \% \mathrm{Mn}-$ $18 \% \mathrm{Cr}$ steel.

small anisotropy and to obtain high strength with lower cold work ratio by high nitrogen and carbon content.

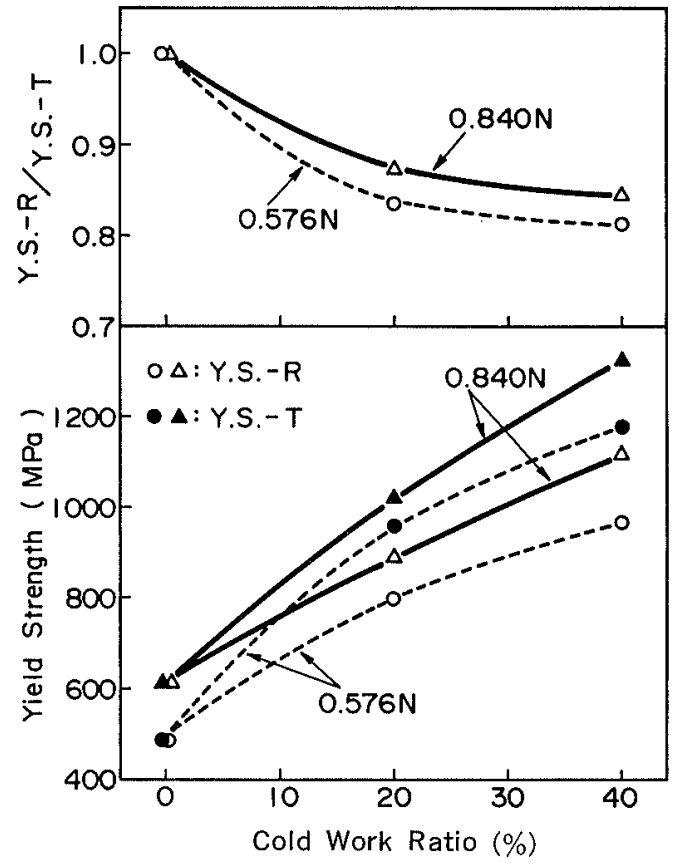

Fig. 10. The relationship between radial and tangential yield strength and cold work ratio.

\begin{tabular}{|c|c|}
\hline Material & SCG test results \\
\hline Key & 0 \\
\hline $0.15,0.25 \mathrm{C}$ & Pitting \\
\hline $0.840 \mathrm{~N}$ & 0 \\
\hline $\begin{array}{l}\text { No crac } \\
95 \% \text { S }\end{array}$ & $400 \mathrm{~h}$ test \\
\hline
\end{tabular}

Condition : $3.5 \% \mathrm{NaCl}, 80^{\circ} \mathrm{C}$

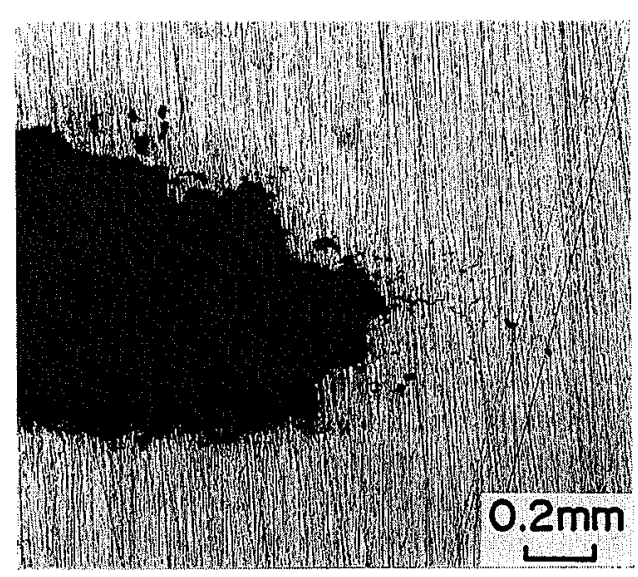

$0.15 \mathrm{C}$

Fig. 11. SCC test results for the $40 \%$ cold worked materials by three point bend test at $80^{\circ} \mathrm{G}$.

\subsection{3. $\mathrm{SGC}$}

SGG susceptibility was investigated for the $40 \%$ cold worked materials by three point bend test at $80^{\circ} \mathrm{C}$ in the $3.5 \% \mathrm{NaCl}$ solution loaded on applied stress of $95 \% Y S$. As the results of the above test, pitting and cracking are detected in the material with 0.15 and $0.25 w t \%$ carbon content by $400 \mathrm{~h}$ and no pitting and cracking detects on $0.840 \mathrm{wt} \% \mathrm{~N}$ material as shown in Fig. 11. Accordingly, high carbon content is not suitable to avoid 'SCQ $18-18$. 


\section{Production of a Trial 18-8 R/R with $Y S 1400$ MPa and Its Material Properties}

A trial 18-18 R/R with YS $1400 \mathrm{MPa}$ by high nitrogen content material was manufactured according to the basic experience of chemical composition and cold working. The $\mathrm{R} / \mathrm{R}$ have typical size for steam power generator, outer diameter and inner diameter are $\phi 1670 \mathrm{~mm}$ and $\phi 1430 \mathrm{~mm}$, respectively.

\subsection{Manufacturing Sequence}

Manufacturing sequence is shown in Fig. 12. The ingot was made with electroslag-remelting (ESR) process in which electrode was made with electric furnace (EF) and vacuum-oxygen-decarburization (VOD).

The composition of $Y S 1400 \mathrm{MPa} \mathrm{R} / \mathrm{R}$ is shown in Table 2.

Hot forging was performed by 3000 and $10000 \mathrm{t}$ presses. In hot forging, it is important to obtain uniform and finer grain size in addition to give essential forging effect as compression of microporosity. The forged ring was then machined, examined by non-destructive test (NDT), solution treated, cold expanded by wedge method and stress relieved.

\subsection{Mechanical Properties of a Trial YS $1400 \mathrm{MPa}$ $R / R$}

Various material properties were investigated with test prolongation of $30 \mathrm{~mm}$ length.

Fig. 13 shows the mechanical properties of $Y S$ $1400 \mathrm{MPa} R / \mathrm{R}$ through the ring thickness. TS and $Y S$ at mid wall which is usually used as typical strength specification of R/R are 1432 and 1427 $\mathrm{MPa}$ on an average, respectively. Strength of outer side is lower than that of inner side. The difference of strength between outer side and inner side depend on the difference of cold work ratio. Average value of $R A$ and $E L$ at mid wall is 53.8 and $18.3 \%$, respectively. Consequently, high ductility, toughness and uniform of mechanical properties were confirmed in the trial $R / R$.

\subsection{Examination of Material Properties on a Trial YS $1400 \mathrm{MPa} R / R$}

3.3.1. Tensile Test Properties

There are clear differences in the mechanical prop- erties of $18-18$ and $18-5$.

Figs. 14 and 15 show the relationship of $E L v s$. YS and $R A$ vs. $Y S$ in tangential direction. At lower strength, $E L$ is similar for $18-18$ and $18-5$. However, $E L$ is higher for 18-18 in the important high strength region. Consequently, 18-18 has higher ductility and toughness than 18-5.

The variation of $T S$ and $Y S$ of $18-18$ and 18-5 with test temperature are illustrated in Fig. 16. TS and $Y S$ decrease as test temperature increases, as well

Table 2. Chemical compositions of a trial $18 \% \mathrm{Mn}-$ $18 \% \mathrm{Cr}$ retaining ring.

\begin{tabular}{ccccc}
\hline $\mathrm{G}$ & $\mathrm{Si}$ & $\mathrm{Mn}$ & $\mathrm{Cr}$ & $\mathrm{N}$ \\
\hline 0.043 & 0.31 & 19.09 & 19.37 & 0.709 \\
\hline
\end{tabular}

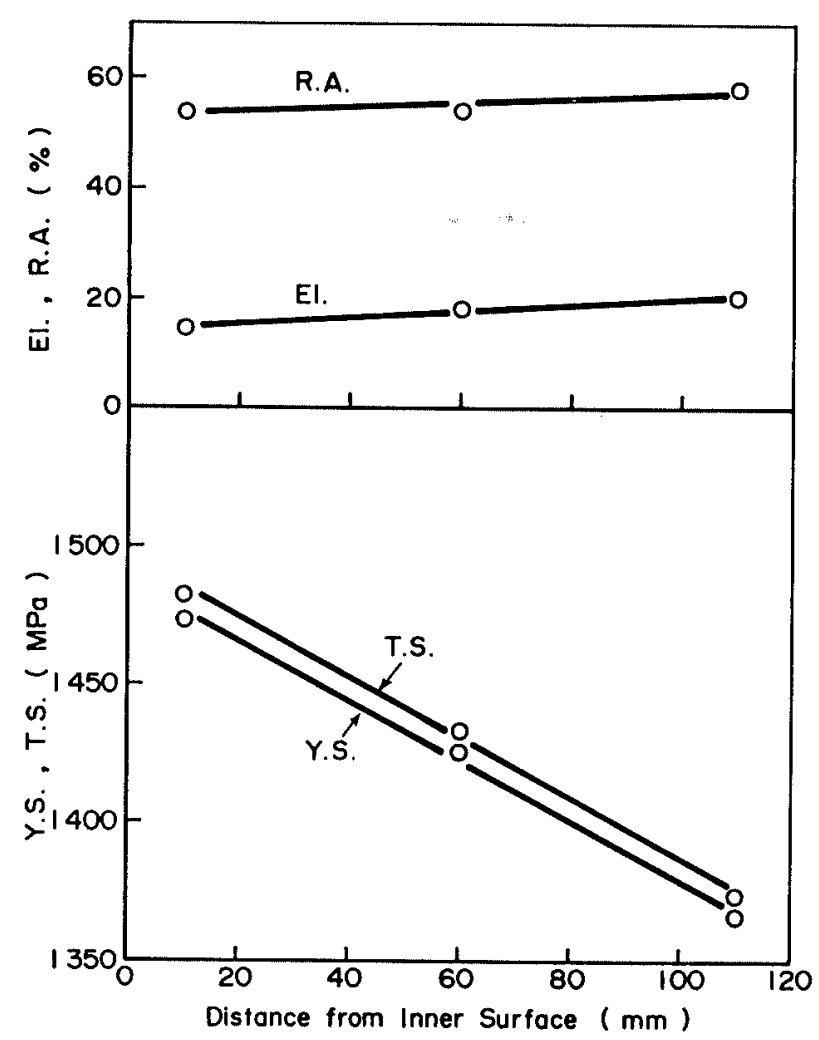

Fig. 13. Mechanical properties of a trial yield strength $1400 \mathrm{MPa}$ retaining ring through the ring thickness.
Fig. 12.

Manufacturing sequence of $18 \%$ $\mathrm{Mn}-18 \% \mathrm{Cr}$ retaining ring.

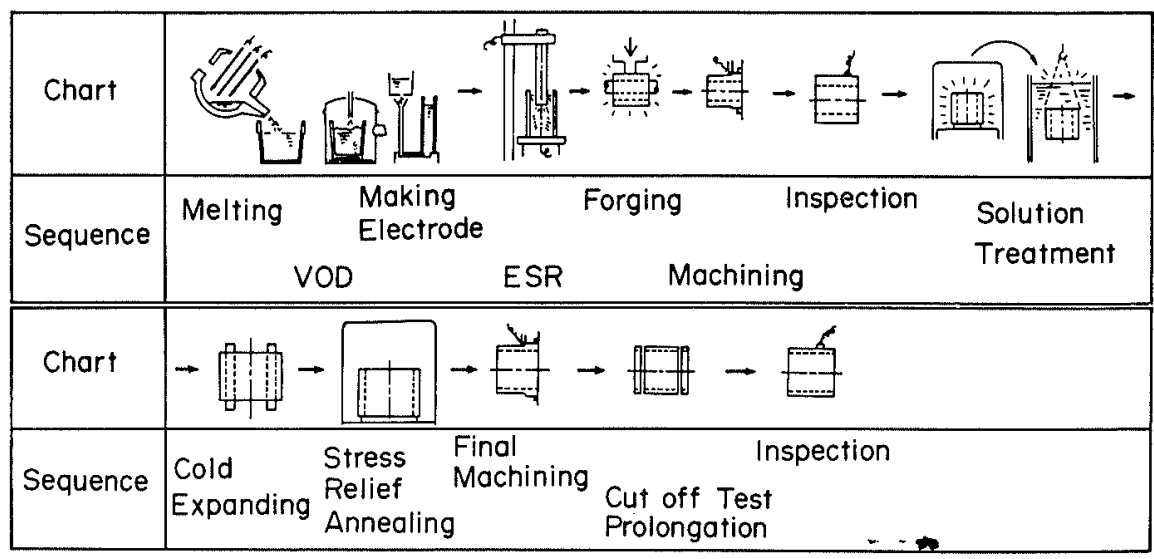


known. The TS and YS decrease of 18-18 is larger than that of $18-5$ at the temperature from room temperature to about $200^{\circ} \mathrm{C}$. The peculiar $Y S$ and $T S$ decrease of 18-5 shall be explained by strain aging due to high carbon content of $18-5 .{ }^{7)}$

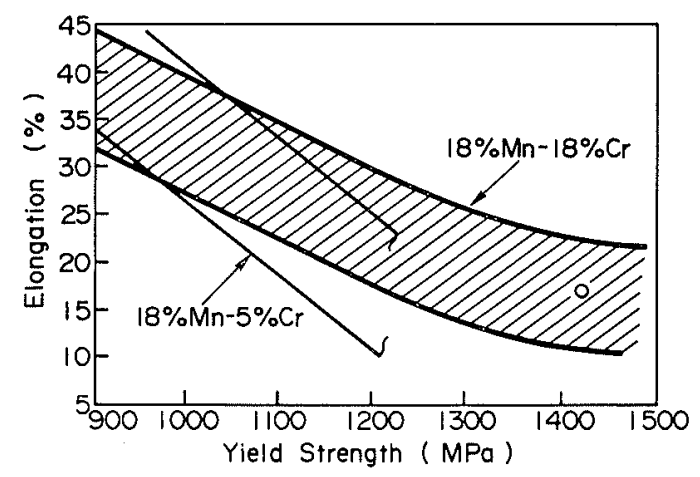

$O$ : Actual results of the trial ring

Fig. 14. Relationship between tensile strength and yield strength.

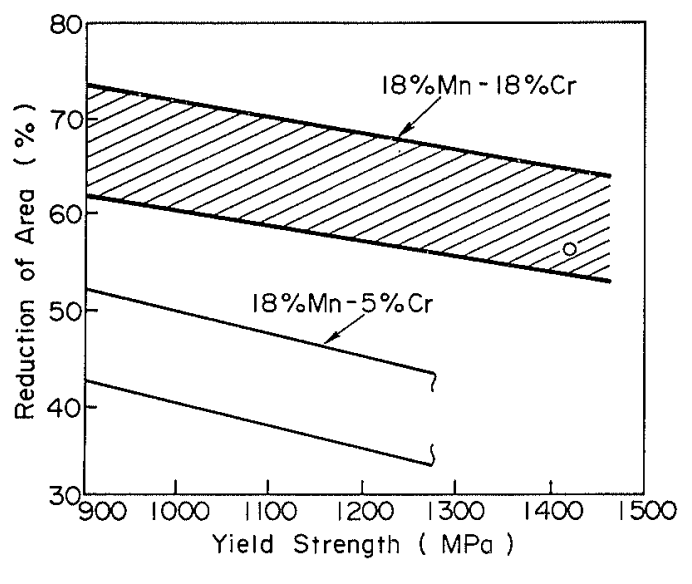

$O$ : Actual results of the trial ring

Fig. 15. Relationship between reduction of area and yield strength.

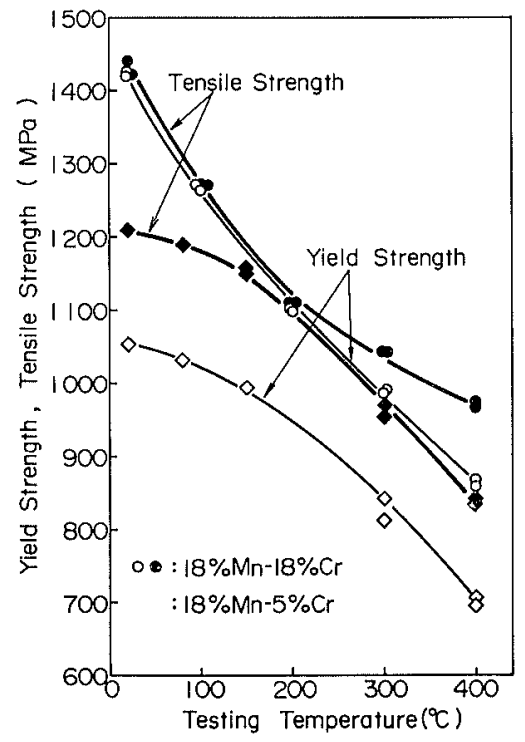

Fig. 16. The variation of tensile strength and yield strength with test temperature of $18 \% \mathrm{Mn}-18 \% \mathrm{Cr}$ and $18 \% \mathrm{Mn}-5 \% \mathrm{Cr}$ steels.

\subsubsection{Anisotropy of Tensile Properties}

Fig. 17 shows anisotropy of $Y S$, that is, radial/ tangential ratio of $Y S$ at mid wall of $18-18 \mathrm{R} / \mathrm{R}$ as a function of tangential $Y S$. The ratio decreases as tangential $Y S$ increases.

The radial/tangential ratio of $Y S$ of high nitrogen content material is higher than one of low nitrogen material. So high nitrogen content material is good for the isotropy of higher strength $18-18 \mathrm{R} / \mathrm{R}$.

\subsubsection{Fracture Toughness}

Fig. 18 shows comparison of fracture toughness of 18-18 and 18-5 which are determined by $J_{\text {IG }}$ using ITCT specimens. Fracture toughness of $18-18$ is higher than that of 18-5. Anisotropy of fracture toughness is not observed, though fracture toughness decreases as $Y S$ increases. The fracture toughness of 18-18 is very high.

\subsubsection{Fatigue Strength}

Test results of low cycle fatigue of 18-18 as a function of test specimen direction and $Y S$ range are shown in Fig. 19 with $18-5$ data. Fatigue strength increases with increasing $Y S$, and fatigue strength of tangential direction are higher than radial direction which shall be explained by anisotropy of tensile strength.

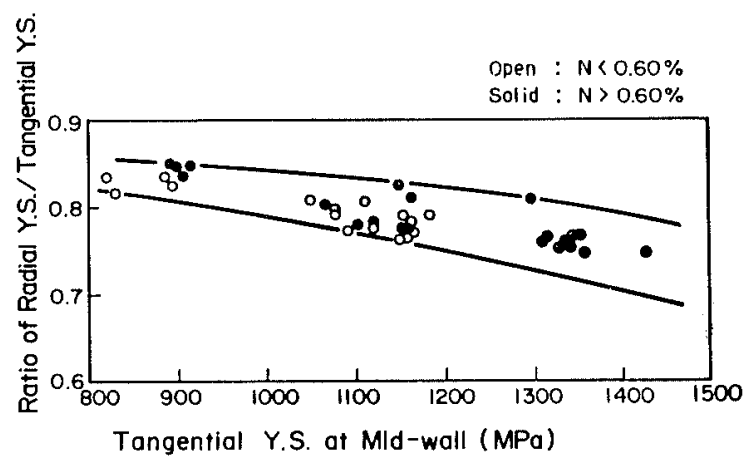

Fig. 17. Anisotropy of mechanical properties of $18 \% \mathrm{Mn}-$ $18 \% \mathrm{Cr}$ as a function of tangential $Y S$.

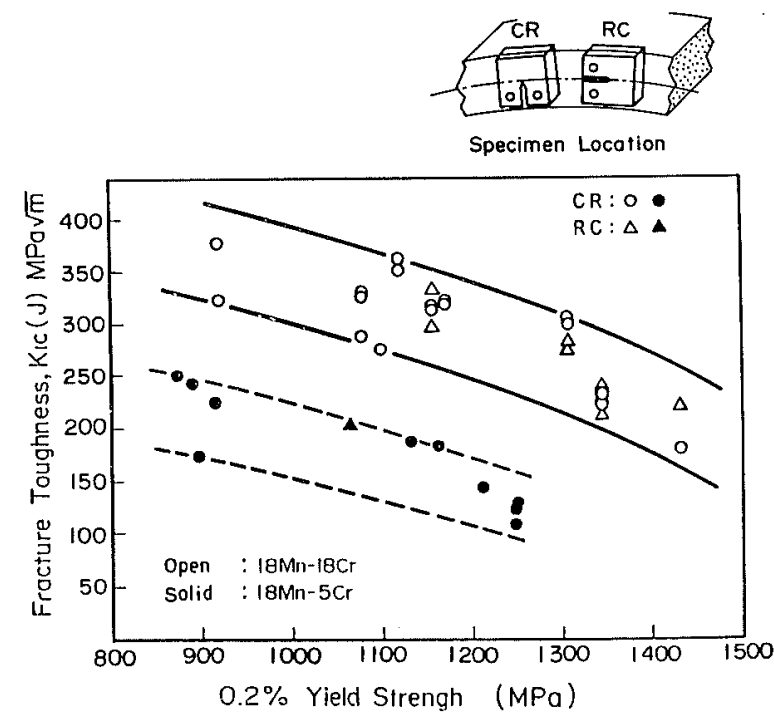

Fig. 18. Fracture toughness and yield strength of $18 \% \mathrm{Mn}-$ $18 \% \mathrm{Cr}$ and $18 \% \mathrm{Mn}-5 \% \mathrm{Cr}$ retaining ring materials.

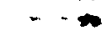


ISIJ International, Vol. 30 (1990), No. 8

Table 3. SCC initiation test results of the $18 \% \mathrm{Mn}-18 \% \mathrm{Cr}$ retaining ring material with yield strength $1400 \mathrm{MPa}$.

\begin{tabular}{cccccccc}
\hline \multicolumn{3}{c}{ Chemistry (wt\%) } & & & & \multicolumn{2}{c}{ SCC initiation test } \\
\hline $\mathrm{C}$ & $\mathrm{Mn}$ & $\mathrm{Gr}$ & $\mathrm{N}$ & Direction & $\begin{array}{c}0.2 \% Y S \\
(\mathrm{MPa})\end{array}$ & $\begin{array}{c}\text { Applied stress } \\
(\mathrm{MPa})\end{array}$ & Results \\
\hline & & & & & & $999.5(70 \%)$ & $5162 \mathrm{~h}$ \\
0.043 & 19.09 & 19.37 & 0.709 & Tangential & 1427.8 & $1285.0(90 \%)$ & No crack \\
\hline
\end{tabular}

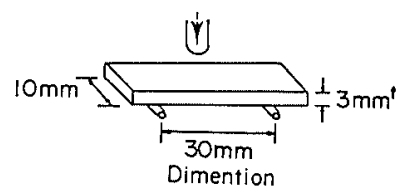

Test method : Three point bend test Environment: $3.5 \% \mathrm{NaCl}$

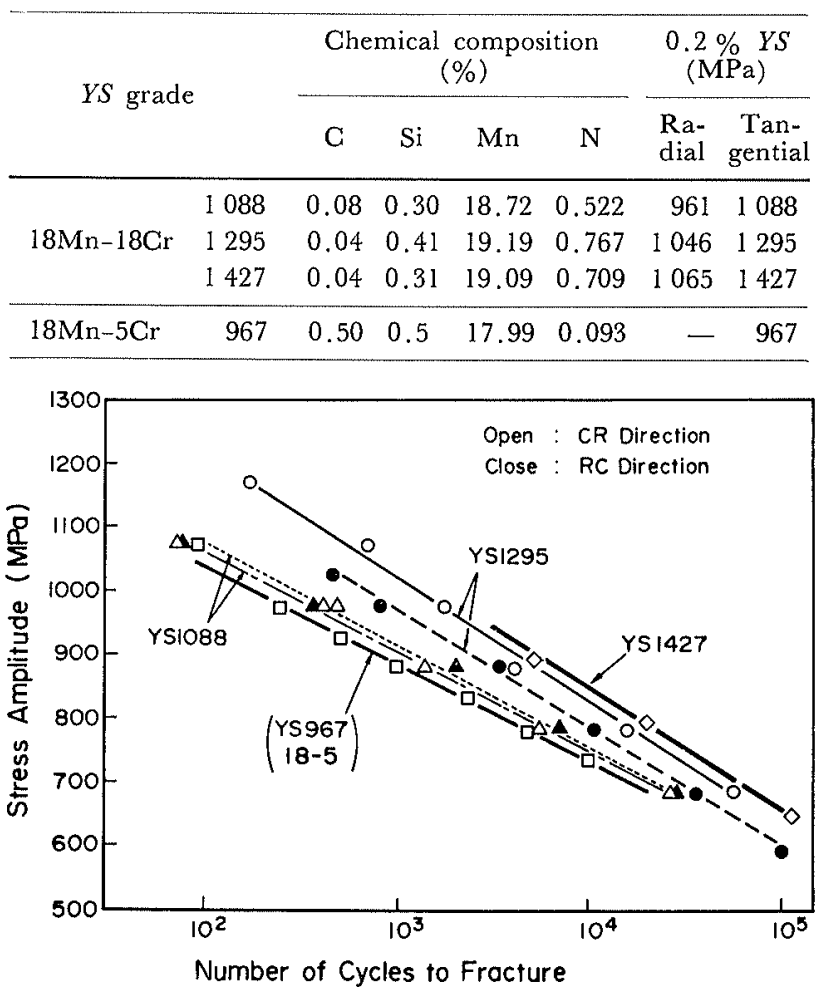

Fig. 19. Low cycle fatigue strength of $18 \% \mathrm{Mn}-18 \% \mathrm{Cr}$ and $18 \% \mathrm{Mn}-5 \% \mathrm{Cr}$ as a function of test specimen direction and yield strength tested with 0 mean stress.

\subsection{5. $\quad \mathrm{SCC}$}

Test results of $\mathrm{SCG}$ initiation for a trial $\mathrm{R} / \mathrm{R}$ are shown in Table 3. Gracks and pitting are not detected on specimen after $5162 \mathrm{~h}$ under applied stress $1356.4 \mathrm{MPa}$ which means $95 \%$ of $Y S$ at mid wall.

\section{Conclusion}

Retaining ring for electric generator is required to have non-magnetism, high strength, high ductility SCG resistance. Several kinds of materials for nonmagnetic $R / R$ have been developed and recently $18 \% \mathrm{Mn}-18 \% \mathrm{Cr}$ austenitic steel which has been de- veloped to improve susceptibility to SGG of $18 \% \mathrm{Mn}-$ $5 \% \mathrm{Cr}$ austenitic steel has begun to use. $18 \% \mathrm{Mn}-$ $18 \% \mathrm{Cr}$ steel contained high nitrogen content has been investigated as the material with high strength, high ductility and SCG resistance. Following results were obtained on fundamental experience and manufacturing a trial ring.

(1) Yield strength of solution treated $18 \% \mathrm{Mn}$ $18 \% \mathrm{Cr}$ steel is higher as nitrogen content increases.

(2) $18 \% \mathrm{Mn}-18 \% \mathrm{Cr}$ steel with high nitrogen content offers higher yield strength with smaller cold work ratio.

(3) A smaller cold work ratio results in higher ductility and less anisotropy.

(4) High carbon content is not suitable to avoid $\mathrm{SCG}$ of $18 \% \mathrm{Mn}-18 \% \mathrm{Cr}-\mathrm{N}$ retaining ring material.

(5) SCG of $18 \% \mathrm{Mn}-18 \% \mathrm{Cr}$ steel with yield strength $1400 \mathrm{MPa}$ shows good performance in a corrosion environment.

\section{Acknowledgments}

The authors are grateful to Dr. K. Ohnishi (Muroran Plant) to be given the chance and guidance to the research works on high strength retaining ring materials and Messrs. Y. Murakami (Muroran Plant), I. Iwata (Muroran Plant) and T. Hatano (Research Lab., Muroran Plant) for performing experiments and analyses of data.

\section{REFERENCES}

1) M. O. Speidel: Corrosion, 32 (1976), 187.

2) R. Viswanathan: Workshop Proceedings: Retaining Rings for Electric Generators, Palo Alto, EPRI Rep. EL3209, Aug., 1983.

3) W. M. Small and R. D. Pehlke: Trans. Metall. Soc. AIME, 242 (1968), 2501.

4) M. Tari, T. Inoue and Y. Okada: Toshiba Rev., 33 (1978), 655.

5) D. L. Newhouse etc:: ASTM 68th Annual Meeting, June 13-18, 1965, ASTM.

6) C. M. Hsiao and E. J. Dulis: Trans. Am. Soc. Met., 50 (1962), 773.

7) K. Ohnishi and J. Ishizaka: Tetsu-to-Hagané, 63 (1977), 2362. 